Article

\title{
Conceptualising and Modelling E-Recruitment Process for Enterprises through a Problem Oriented Approach ${ }^{\dagger}$
}

\author{
Saleh Alamro, Huseyin Dogan *(D), Deniz Cetinkaya, Nan Jiang and Keith Phalp \\ Faculty of Science and Technology, Bournemouth University, Fern Barrow, Poole, Dorset BH12 5BB, UK; \\ salamro@bournemouth.ac.uk (S.A.); dcetinkaya@bournemouth.ac.uk (D.C.); \\ njiang@bournemouth.ac.uk (N.J.); kphalp@bournemouth.ac.uk (K.P.) \\ * Correspondence: hdogan@bournemouth.ac.uk; Tel.: +44-1202-962491 \\ † This paper is extended version of conference paper "Alamro, S.; Dogan, H.; Cetinkaya, D. and Jiang, N. (2018). \\ Problem-Oriented Conceptual Model and Ontology for Enterprise e-Recruitment."
}

Received: 20 September 2018; Accepted: 25 October 2018; Published: 29 October 2018

\begin{abstract}
Internet-led labour market has become so competitive it is forcing many organisations from different sectors to embrace e-recruitment. However, realising the value of the e-recruitment from a Requirements Engineering (RE) analysis perspective is challenging. This research was motivated by the results of a failed e-recruitment project conducted in military domain which was used as a case study. After reviewing the various challenges faced in that project through a number of related research domains, this research focused on two major problems: (1) the difficulty of scoping, representing, and systematically transforming recruitment problem knowledge towards e-recruitment solution specification; and (2) the difficulty of documenting e-recruitment best practices for reuse purposes in an enterprise recruitment environment. In this paper, a Problem-Oriented Conceptual Model (POCM) with a complementary Ontology for Recruitment Problem Definition (Onto-RPD) is proposed to contextualise the various recruitment problem viewpoints from an enterprise perspective, and to elaborate those problem viewpoints towards a comprehensive recruitment problem definition. POCM and Onto-RPD are developed incrementally using action-research conducted on three real case studies: (1) Secureland Army Enlistment; (2) British Army Regular Enlistment; and (3) UK Undergraduate Universities and Colleges Admissions Service (UCAS). They are later evaluated in a focus group study against a set of criteria. The study shows that POCM and Onto-RPD provide a strong foundation for representing and understanding the e-recruitment problems from different perspectives.
\end{abstract}

Keywords: enterprise recruitment; problem definition; e-recruitment

\section{Introduction}

Recruitment is a key strategic opportunity for achieving a competitive advantage over rivals [1,2]. Given that talent is rare, valuable, difficult to imitate, and hard to substitute, organisations that better attract this talent to fill their job vacancies should outperform those that do not [3]. Recruitment is the practice of attracting sufficient numbers of qualified individuals on a timely basis to fill job vacancies within an organisation [4]. It is very important since it is the primary way of influencing the performance and diversity of individuals in an organisation. It ensures the initial high quality abilities of recruits necessary for work performance [5]. It also influences the demographic composition of the workforce to meet the organisation's strategic, legal and social goals [6]. It is regarded as an essential means to influence post-hire employee retention [7]. 
The Internet-driven global labour market, combined with many forces, such as a higher educational level of the new generations, strong economic situations and a low unemployment rate, has become very competitive [8,9]. This, in turn, puts a great deal of pressure on organisations from different sectors to change their traditional recruitment practices towards more innovative, high-quality, customised, and timely e-recruitment solutions [9-11]. In the military sector, for instance, the migration from old compulsory military recruitment to an all-volunteer force relying on labour market has increasingly pushed the military organisations to get into the continuum $[8,12,13]$. E-recruiting is defined as any recruitment practice that an organisation conducts using web-based solutions [14,15]. Among the different methods of e-recruiting, web recruiting (i.e., use of corporate website) is the most commonly used e-recruiting method [4]. E-recruiting can bring value for organisations including being reliable in attracting a diverse and qualified group of job seekers, agile in filling vacancies, cost-effective, rapidly responding to job seekers' changing needs and market opportunities, and flexible in normal and exceptional circumstances [16].

The current maturity of information and communication technologies (ICTs) and the recent developments in design processes enable a relatively simple and reliable transforming of the conventional recruitment practice into e-recruitment solution $[13,17]$. To be innovative, the focus should be shifted from the e-solution space to the problem space where the desired effects (i.e., requirements) that an organisation wishes to be brought by the e-solution in the recruitment practice exist $[18,19]$. With the help of Requirements Engineering (RE), the RE activities of the e-solution must be anchored to the domain knowledge of real-world recruitment problem so that the quality of the e-solution to be delivered can then be analysed [20-23]. This front-end part of RE is called problem definition [24] or problem description $[25,26]$.

Problem definition refers to how problems or concerns are represented: what problem elements should be included, what relationships there are among these elements, and how these selections might vary over problem types [24,25]. Such a problem representation is created for structuring problem domain knowledge and orienting it towards RE in a systematic manner [27]. Hence, it offers an established problem definition and serves as a basis for eliciting and reasoning about requirements from different stakeholder perspectives [21,28]. For instance, relevant stakeholders using this representation could be asked to identify the flaw, conflicts, incompatibility, and difficulties that define a problematic situation thereby effectively and efficiently informing complete and consistent requirements. As a result, the problem representation affects the quality of the requirements based on which the e-solution systems are built. It has been argued that, if stakeholders do not agree with the choice of problem representation, it is unlikely that they will ever agree with any statement of the requirements [20,25]. These poor requirements largely account for the cancellation of e-solution development projects or the subsequent failure in building a successful e-solution $[29,30]$.

However, in large-scale, trans-national and multi-demographical organisations that are engineering-focused and need reliable and long-lasting e-solutions, it seems that problem definition is very complex and prone to failure [22,27]. This research was originally driven by the challenges faced in realising the value of a real e-recruitment project from the military sector referred to as Secureland Army Enlistment. The project relates to the non-officer enlistment process in the Secureland's Army (SA). Three main challenges related to some knowledge gaps in the research literature can be summarised as:

- $\quad$ The difficulty in scoping recruitment problem [31,32];

- The difficulty in representing and understanding of real-world recruitment problem [6,33]; and

- The difficulty in systematically transforming the problem domain knowledge into the specification of e-recruitment [22,23].

The practical problem addressed in this paper is that the ill-representation and understanding of recruitment problem impedes the realisation of the value of e-recruitment. Therefore, the paper proposes a Problem-Oriented Conceptual Model (POCM) for conceptualising and defining recruitment problem root concepts from an enterprise perspective facilitated by an ontology (Onto-RPD) to 
elaborate these concepts towards a comprehensive recruitment problem definition. During this study, three case studies, including the Secureland Army Enlistment, were analysed, and various problems were identified to develop the conceptual model and the corresponding ontology. This work provides a valuable contribution into the understanding of recruitment problem from different perspectives, and can deliver guidance in a systematic manner to inform the requirements elicitation and analysis towards e-recruitment solutions.

The remainder of this paper is organised as follows: The literature review and background information are presented in Section 2. The research methodology based on three case studies is explained in Section 3. Based on the analysis of case studies, the POCM and Onto-RPD are proposed in Section 4. The evaluation results of the POCM and Onto-RPD are discussed in Section 5. Finally, conclusions are drawn and future work is suggested in Section 6.

\section{Background and Related Work}

\subsection{Recruitment and E-Recruitment}

A great deal of research from both Human Resources (HR) and Industrial and Organisational (I/O) psychology domains has been conducted to define recruitment. However, there has been no consensus on its definition. Randall [34] stated that recruitment is "the set of activities through which the people and the organisations can select each other based on their own best short and long term interests". This definition highlights recruitment from the perspectives of the two key players: organisation (i.e., employer) and people (i.e., job seekers). However, from an organisation-based perspective, Barber [35] defined recruitment as "the practices and activities carried on by the organisation with the primary purpose of identifying and attracting potential employees". He delineated three phases of recruitment: (a) generating applicants; (b) maintaining applicant status; and (c) influencing job choice decisions.

Breaugh [7] distinguished between two types of recruitment: internal, in which a job applicant is a member of the employing organisation; and external in which a job applicant is not a member of the employing organisation. Internal recruitment is similar to employee promotion and move. However, external recruitment is defined as the organisational activities that are intended to: (a) bring a job opening to the attention of potential job candidates who do not currently work for the organisation; (b) influence the number and/or the types of applicants to apply for the job opening; (c) influence their interest in the position to stay until a job offer is extended; and (d) influence their interest to accept a job offer [7]. Likewise, Rynes [36] stated that recruitment is the activities designed to influence the number and type of applicants who apply for a job and accept job offers. Another definition stressing timing is the practice of attracting sufficient numbers of qualified individuals on a timely basis to fill job vacancies with an organisation [4].

Saks [31] described recruitment as "the set of actions and activities taken by an organisation in order to identify and attract individuals to the organisation who have the capabilities to help the organisation realising its strategic objectives." This definition implicitly combines the activity of selection in which the capabilities and qualifications of individuals are evaluated against who apparently owns those capabilities that help the organisation in realising its strategic objectives. In contrast to this, Gatewood et al. [6] defined another type of recruitment called hiring. Hiring refers to the type of employment in which job offers are extended with no evaluation of the applicant's capabilities and qualifications [6]. This is often carried out when an organisation desperately needs applicants to fill unskilled or semi-skilled positions within a limited time.

Looking to recruitment from a broad sense, Philips and Gully [37] defined strategic recruitment as "the practices that are connected across the various level of analysis and aligned with firm goals, strategies, context, and characteristics." They suggested that strategic recruitment overlaps with four complex disciplines: Resource-Based Theory (RBT); Strategic Human Resources Management (SHRM); 
human capital; and levels of analysis [37]. The work of Philips and Gully [37] highlights the need to extend the focus on recruitment from a higher level of analysis as same as the SHRM approach.

The review of the abovementioned recruitment definitions [4,6,31,32,34-37] gives insights into the common and divergent characteristics of recruitment as follows:

- It involves specific activities and actions that are undertaken to achieve particular outcomes.

- It indicates the importance of generating a pool of applicants with desirable capabilities.

- It addresses the interest of relevant stakeholders such as organisation and applicant to fill vacancies.

- It addresses the need to increase the probability that applicants will apply, stay, and accept a job offer.

- It indicates the overlap between recruitment and the selection activity by acknowledging that those persons who are attracted to the organisation might/might not have the capabilities desired. Hence, it is the purpose of selection to determine whether applicants have the required capabilities.

- It distinguishes between internal and external recruitment.

- It distinguishes between recruitment and hiring.

- It indicates the overlap between pre-hire outcomes of recruitment (e.g., filling vacancies by the qualified applicants) and post-hire outcomes (e.g., employee retention and work performance).

- It asserts the strategic focus on recruitment thereby making it clear that recruitment can and should play an important role in helping an organisation achieve its strategic objectives.

In this research, we focus on recruitment as enterprise and analysis of different interests from different enterprise stakeholders' perspectives. We accept that the activity of selection is included within recruitment. In addition, we focus on external recruitment rather than internal one; recruitment rather than hiring; and pre-hire outcomes rather than post-hire outcomes.

E-recruitment is defined as the use of the Internet to attract potential employees to an organisation and hire them [38]. Dhamija [39] described e-recruitment as "the practice whereby the online technology is used particularly websites as a means of attracting, assessing, interviewing, and hiring personnel." E-recruitment could be defined as any recruiting process that an organisation conducts using Web-based tools [14,15]. There are some common methods of e-recruitment. First method is Web recruiting (use of the organisation's Web site) is the most commonly used e-recruiting method [4,38]. The second method is the use of Internet job boards [40-42] where organisations rely upon third-party recruiters (e.g., CareerBuilder.com, Monster.com, and HotJobs.com). The third is social media recruitment [43].

Even though the contributions of these recruitment methods are varied, the common advantages that e-recruitment can offer are: savings in time, money, and resources; the outreach potentiality to a diverse broader group of job seekers; establishing a brand identity; more communicative and adaptive to job seekers' changing needs and market opportunities, better service and applicant satisfaction; and more flexible in normal and exceptional circumstances $[4,16]$.

Recruitment is a foundational input of organisational effectiveness [5,37,44]. Competitive advantage is rooted in the individual and organisational capabilities that are leveraged for strategic execution [2]. Since recruitment influences these capabilities, it is a key source of competitive advantage [37,45]. Recruitment is the first entrance to influence the characteristics and quality of new employees [5]. It has also implications for all other human resources activities [6]. For example, the type of applicants attracted has implications for selection and training activities.

The e-recruitment has made a new competitive environment for organisations to rethink and adapt technology to increase effectiveness and efficiency of recruitment practice. Combined with various challenges such as the increased importance of human capital, the ubiquity of technologies, the increased level of qualifications with new generations, strong economic situations, and less unemployment rates $[8,16,46]$, recruitment has been marked as a top priority $[31,43,47]$. Research has offered evidence about the rationale behind this increased interest in e-recruitment. First, passive 
recruitment, which implies people to make themselves available to employers, is outmoded. This may account for why many organisations have experienced substantive crisis in attracting high-quality employees [4]. Second, Scheweyer [48] reported that the demand of e-recruitment has been rapidly increasing due to the competitive advantages it offers. This, in turn, has put a great deal of pressure on organisations to shift into e-recruitment [9-11]. Third, e-recruitment allows job seeker to be more selective in their job choices which increasingly forces organisations to adopt more innovative ways to satisfy their needs [43].

\subsection{Problem-Oriented RE and Problem Definition}

The concept of problem is central in research on systems and software engineering [25]. More broadly, it presents in every study requires action-oriented thought [24]. Despite this centrality and its widespread use, it is still not clearly defined. Osigweh [49] stated that problem is a vague concept: the more the word "problem" is used for everything, the less we know what it means. One common definition is that it is a gap, difference, or disparity between what is and what might/should be [24,50]. Another definition, by Agre [51], is that a problem is an undesirable situation that is significant to, and may be solvable by, some agent, although probably with difficulty. According to Landry [50], the key characteristics of the presence of problem can be concluded as follows:

- An unsatisfactory situation

- The existence of gap between preferences and reality

- The importance of closing this gap (i.e., solution)

- The expected difficulty or uncertainty arising from where the means to close the gap are either not obvious or not immediately available

- A sense of minimal control (e.g., available resources) over situation or event

- Has an owner/solver

- Changes over time

- Has a boundary

- Interrelated with another construct, "opportunity", which draws attention to potential goods, instigating thoughtful problem solving activity

Given that requirements define a problem, RE can carry various synonyms such as problem analysis [52], requirements analysis [53,54], or problem domain analysis [18]. Davis [52] defined the term problem analysis as the activity that encompasses learning about the problem to be solved, understanding the needs of potential users, trying to find who the user really is, and understanding all the constraints on the solution. However, according to Kotonya and Sommerville [55], problem analysis cannot rely only on learning the details of a specific problem that requires some kind of systems solution. Instead, it requires a focus on understanding the problem domain, including business context and stakeholders' needs, which necessitates an extensive elicitation task. Therefore, Kovitz [53] defined the term requirements analysis as learning the problem and the problem domain from the customer, and communicating this information to the rest of the development staff by writing a requirements document. A quite similar definition by Kovitz [53], coming from Bray [18], refers to problem domain analysis. Bray [18] defined it as the achievement of understanding problem domain and the documentation of the characteristics of that domain and the problems (requiring solution) that exist within that domain. According to Wieringa [56], if RE is to define a problem, then requirements should describe what the problematic phenomena are, what the causal relationships between these phenomena are, by which norms these phenomena are problematic, and which stakeholders have these norms. From common sense, it can be said that all aforementioned definitions obviously serve to introduce the concept of RE as problem definition, learning about problem domain and finding out what the problems to be solved are.

A problem-oriented view of RE, namely problem definition, refers to how problems or concerns are represented: what problem elements should be included, what relationships among these elements are, 
and how these selections might vary over problem types [25,57]. Given the complexity of a real-world problem, there is no representation model by which the various elements that constitute a problem can be comprehensively included [58]. Hence, each model has some advantages and limitations.

One key example of these representation approaches is goal modelling [59]. Goal modelling is based on the premise that in collaborative work situations, people are aware of and share common goals and act towards their fulfilment [27]. Hence, the problems associated with business structure, resources, processes, and their supporting systems that inhibit the achievement of these goals can be defined [59]. However, a real-world problem concerns the goals of humans which is not simple to model for several reasons: (a) they are not known in advance; (b) they are often abstract and imprecise and can evolve during the life of a project; and (c) the means that lead to goal achievement are not known beforehand. A second example of these approaches is the problem frames [25], in which frequently occurring problem structures are identified and related to a problem frame. This frame captures the characteristics and relationships of the parts of the world it is concerned with, and the concerns and difficulties that are likely to arise. This helps to focus on the problem space instead of moving into the solution space. However, it is criticised being limited in scope focusing on the objective aspects of software problems [60].

A third problem representation approach is Enterprise Architecture (EA). The concept of EA has evolved to address two key problems [61]. The first problem is to manage the increasing complexity and change in IT systems [62]. The second problem is the increasing difficulty in realising business value with those systems [61]. To solve these key problems, a bundle of EA reference frameworks was proposed. According to Roger [61], the leading ones are Zachman Framework [28], The Open Groups Architecture Framework (TOGAF), and Federal Enterprise Architecture (FEA). According to Zachman [62], today's information age with the increased complexity and change in the global market needs a holistic view that addresses the wide range of business requirements rather than just focusing upon technical solutions. Hence, it is not an IT issue [62-64]; however, it is a problem definition issue [18,56,62]. According to Zachman [62], an EA, therefore, needs a structure (i.e., representation) that establishes a problem definition reference and guides the transformation process (i.e., methodology) towards the solution. Without such a structure, transformation processes will be ad hoc, fixed and dependent on practitioner skills [62].

Despite the insights given by the Zachman's framework (i.e., the importance of problem representation), the framework has some limitations in regard to the recruitment research problem. First, the framework lacks a step-by-step supportive process for enterprise engineering [61]. The framework is a structure (i.e., problem representation) and not a transformation process [28]. Second, the framework builds on the argument that the conventional architecture representations of the manufacturing and constructions can be analogously applied into a complex real-world problem (e.g., recruitment). According to Gaver [65], this conceptual argument is faulty and incomplete. In general, a real-world problem is not an ordinary system, such as a machine or a building, to be structured and engineered. In particular, recruitment problem has many social and subtle features that cannot be easily represented in a reduced form as same as that of the Zachman's framework. These social features are often neglected or trivialised [66].

\subsection{Representation Models of the Recruitment Problem}

From the cognitive view, problems are conceptual entities that do not exist in the world, but they must be externalised (i.e., expressed), thus represented towards solution-oriented thought [24,57]. Problem representation enables problem domain knowledge, which is, in turn, crucially important in problem solving $[21,23]$. This task is very difficult for a real-world problem due to the various aspects that constitute it $[22,25,27,67]$. Hence, there is no reference model by which all these various aspects can be comprehensively represented $[58,68]$. Therefore, recruitment problem can be expressed by a chosen representation that is somehow grounded in reality; agreed on by all stakeholders; and best suited for problem solving $[50,67]$. Many criteria have been proposed for assessing the quality of 
such representation, such as validity and generativity [24,68]; abstraction [21,69]; viewpoints [69]; and expressiveness and communicativeness [68]. However, the quality varies based on many aspects of real-world problem such as the context and complexity of a real-world problem, the type of business, the type of project, and the feature of analysis [69-71].

There are several descriptive and prescriptive recruitment models proposed for conceptualising recruitment problem. The most cited ones are Rynes's [35] model for future recruitment research, Saks's [31] dual-stage model of the recruitment process, and Breaugh and Starke's [7] model for the organisational recruitment process. While these models address some aspects of recruitment problems, they are strongly solution-oriented, focusing on what and how rather than why. Ployhart [33] (p. 869) commented on the research-practice gap of recruitment saying "it seems organisational decision makers do not understand staffing (recruitment) or use it optimally." We believe that because recruitment problem has never been completely represented, it has never been correctly understood. In this regard, it has been widely reported that, when stakeholders ask for new features or capability, they quite often state their needs as an implementation (i.e., solution-based) [60,72].

It has been widely suggested that a better representation of the recruitment problem should rely in the first instance on an appreciation of its complexity $[5,7,31,33]$. This complexity stems from a set of cognitive, social and organisational variables involved and the nature of their relationships [7,32,35].

To respond to the gap with recruitment problem representation, this paper develops two artefacts: a problem-oriented conceptual model (POCM) and a related complementary ontology (Onto-RPD) for representing real-world recruitment problem. POCM, being problem-oriented, contextualises the various recruitment problem concepts and their intricacies (i.e., relationships) to provide a better understanding of the variety of recruitment problem definitions that might be proposed in a given situation. Onto-RPD, in turn, supports the POCM concepts by linking them with the other recruitment problem space concepts. By means of these two artefacts, we believe that the gap in recruitment problem representation can be closed. First, the essential methodology based on which the artefacts are developed is Soft System Methodology (SSM). This methodology enables encompassing of the complexity of real-world problem situation by providing representations that relatively correspond to the reality and represent different stakeholders' perspectives. Second, the artefacts will delay solution consideration of a recruitment problem situation until a good recruitment problem domain knowledge is obtained. For example, a recruitment analyst can define, analyse, and match the recruitment problems in a given situation with their counterparts on POCM, while addressing the problem space (i.e., context) in which these problems exist at the same time using Onto-RPD. Third, the artefacts support an adequate representation of real-world recruitment problem by meeting the most important criteria for assessment.

\section{Research Methodology}

The research approach used in this study is design science. According to Hevner et al. [73], design science creates new artefacts for solving practical problems. These artefacts can be methods, models, constructs, frameworks, prototypes or IT systems, which are introduced into the world to make it different, to make it better [74]. Design science is, therefore, the process to generate these artefacts and test hypotheses about them, i.e., artefacts that can, when introduced, solve problems for a practice and change its future behaviour [75]. Hence, the solution needs to be evaluated to assess its ability to solve a practical problem as well as to fulfil stated requirements [73]. In the literature, different strategies and approaches have been presented for design science processes and conducting solution assessment $[73,74,76-78]$. The design science research process carried out in this research includes five research activities as defined by the design science method framework in [74]. These activities and their application are presented below. 


\subsection{Problem Explication}

The first activity in the design science process was to explicate the practical problem that motivates why the artefacts (i.e., in this case, POCM (Problem-Oriented Conceptual Model) and Onto-RPD (Ontology for Recruitment Problem Definition) need to be designed and developed. To explicate this, several research activities and methods were used. First was the extensive review of the SA e-enlistment project using document inspection to identify the various challenges that led to the failure of that project. Second, in relation to those challenges, the literature related to recruitment, e-recruitment, problem definition and representation approaches were reviewed to identify the central issues and knowledge gaps in recruitment research. Third, several problem representation approaches were applied in practice to the SA enlistment case study to reflect and validate those issues and gaps. After the extensive analysis, two problems, among others, were defined as root causes of the failure in the SA e-enlistment project.

The first problem is "the ill-defined scope of recruitment problem space". The related knowledge gap that motivated the research to fill is that "there is a lack of knowledge about enterprise recruitment problem." The second problem is "the ill-representation and understanding of recruitment problem", which impedes the realisation of the value of e-recruitment. The knowledge gap related to this sub-problem is that "there is a lack of knowledge about how recruitment problem is best represented". Hence, the abovementioned artefacts are designed to solve this problem.

\subsection{Requirements Definition}

The second activity in the design science process was to define the requirements of POCM and Onto-RPD. These requirements were used as a basis to evaluate the resulting artefacts and also to guide the construction process of them and any refinement steps. Based on the literature review, the following requirements were selected:

- $\quad$ R1. The artefact(s) should be comprehensive: Comprehensiveness is the degree to which the artefact(s) offers complete knowledge [21,79]. According to Burton-Jones et al. [80], comprehensiveness means the percentage of concepts in the artefact relative to the average for the entire library of concepts in the domain of interest. Osada et al. [69] referred to this as the amount of suitable information included in the artefact. This amount should be large enough and suitable for complete knowledge. However, too huge amount of knowledge is confusing and hard to deal with [69]. For this requirement, in the artefact of the POCM, we referred to the knowledge of problems, sub-problems, and relationships. However, in Onto-RPD, we referred to the knowledge of the various concepts and features related to the problems defined in the POCM.

- $\quad$ R2. The artefact(s) should be generic: Genericity is the degree to which the artefact(s) is shared and sector/domain-independent [79]. The artefact(s) should be shared between diverse stakeholders and activities [79]. Sector or domain independence means that the artefact is not specific to a sector/domain [81,82]. Achieving this requirement facilitates capture, transfer, and reuse of domain knowledge from different domains [83]. Neither POCM nor Onto-RPD requires practitioners to be familiar with the sector or domain in which a recruitment practice is applied.

- R3. The artefact(s) should be consistent: Consistency is the degree to which the artefact(s) has correct and accurate definitions compared to the existing domain knowledge [69,79]. It can be also defined as the degree to which the artefact(s) constitute a coherent unit, i.e., all parts are clearly related [81].

- R4. The artefact(s) should be abstract/granular: Abstraction or granularity is the degree to which the artefact(s) represents a core set of primitives that are partitionable in different levels [21,69,79]. Abstraction is one of the most important criteria in evaluating the representations (i.e., artefacts) of domain knowledge [69].

- R5. The artefact(s) should be perspicacious/generative: Perspicacity or generativity is the degree to which the artefact(s) is easily understood by the practitioners so that it can be consistently 
applied and interpreted across the enterprise [79,80,84]. It is also defined as the ability of the artefact to promote effective decision making or judgement towards problem solving [24]. From a RE perspective, it is defined as the ability of the artefact to promote effective requirements elicitation [60,72].

- R6. The artefact(s) should be minimal: Minimality is the degree to which the artefact(s) contains the minimum number of objects (i.e., terms or vocabulary) necessary $[79,85]$.

\subsection{Design and Development}

The third activity was to design and develop the artefacts that address the explicated problem and fulfils the defined requirements. The POCM and Onto-RPD were jointly designed and developed using Action-Research (A-R) [86] through the plan, act, observe, and reflect activities. The design and development activities are explained in Section 4.

\subsection{Demonstration and Evaluation}

This activity is to use and assess how well the artefacts solve the practical problem considering the previously identified requirements. In the demonstration phase, the POCM and its corresponding Onto-RPD artefacts were used in real-life cases to prove their feasibility. In the evaluation phase, the POCM and Onto-RPD were investigated on whether they solved the problem of research identified and fulfilled the defined requirements. The two phases, demonstration and evaluation, were conducted using a focus group of experts from heterogeneous recruitment-related domains over two sessions, one session for each phase. The demonstration and evaluation activities are explained and the results are presented in Section 5.

\subsection{Research Methods and Resources}

This section describes the various research methods and resources selected for developing the POCM and Onto-RPD artefacts as well as the rationale behind this selection. Figure 1 summarizes which research methods and resources were used during different stages of this research study.

\subsubsection{Action-Research Method}

A- $R$ is a spiral process that allows action (change and improvement) and research (understanding and knowledge) to be achieved at the same time [86]. It emphasises collaboration between researchers and practitioners, and supports the practical problem solving as well as the theoretical knowledge generation [86]. It has much potential for the information systems field being a useful qualitative research method [87]. In regard to using it within the design science framework adopted in this research, there is a growing consensus relating to the similarity between A-R and design science (DS) $[88,89]$. Järvinen [88] compared the two methods and found that they are similar along a string of important parameters. He suggested A-R is more closely combined with DS rather than necessarily a qualitative research per se. He argued that, although DS may be seen as a research method that has been practiced within engineering and natural science, the combination would improve the quality of research by combining relevance and rigor [88]. According to Wieringa and Morali [89], DS research has established itself as an acceptable approach to information systems research by combining a problem-solving cycle with a theory-building cycle. To facilitate such combination, Baskerville et al. [90] integrated both A-R and DS with Checkland's Soft Systems Methodology (SSM) and developed a new approach called soft design science research. Inspired by the work of Baskerville et al. [90], this work integrated A-R, DS, and SSM into building the POCM and Onto-RPD artefacts. 


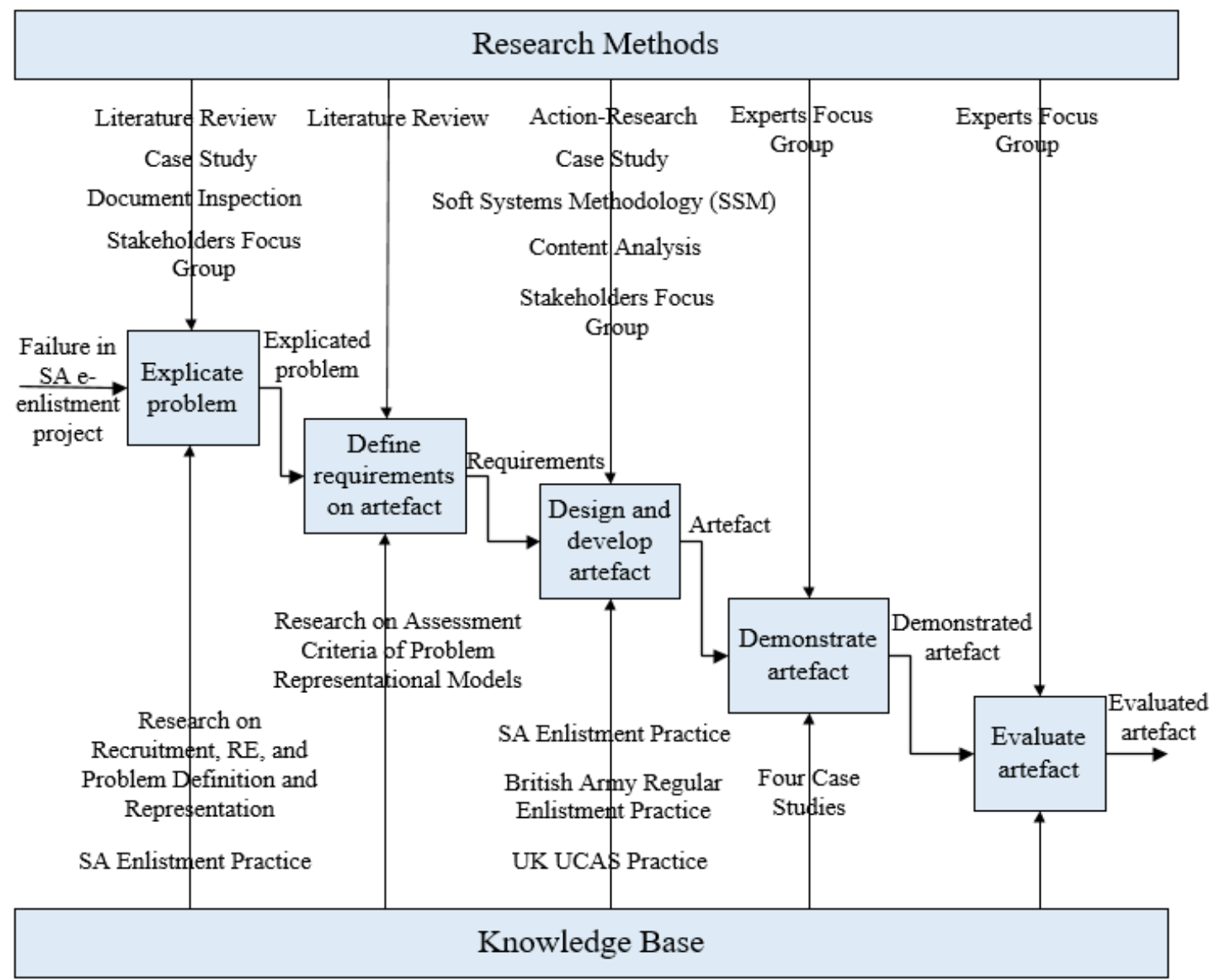

Figure 1. Research methods and resources used during explicate, define, design and develop, demonstrate, and evaluate artefact phases.

\subsubsection{Case Study}

The research was established upon the case study of SA enlistment practice and developed by using two other case studies (BA enlistment case study and UCAS case study). The study (i.e., problem explication phase) was driven by the failure in realising the value of the SA's e-enlistment project with the objective of investigating the various recruitment problems faced in that project. Later in the "design and develop artefact" phase, the problem concepts and relationships were extracted from the SA enlistment practice and refined with the concepts derived from the other two case studies. This type of case studies is exploratory, which is particularly suited to the type of qualitative knowledge available with regards to this research [91]. This type of case study is also used to explore those situations in which the intervention being evaluated has no clear, single set of outcomes [91].

According to Yin [91], a case study method should be considered when: the focus of the study is to answer "how" and "why" questions; there is no or little control over the behaviour of those involved in the study; various contextual conditions are relevant to the phenomenon under study; or the boundaries are not clear between the phenomenon and context. Likewise, the objective of this research was to understand why it is challenging to realise the value of SA's e-enlistment project and how these challenges can be confronted. In addition, little control over those involved in the study and related events was available, and various contextual issues and less clear boundaries between the phenomenon and context exist. Case studies are relatively important when extracting the necessary information and evaluating the artefacts developed. The artefacts were developed and refined through the extraction of some instances from different case studies. A list of features that makes the case studies appropriate was derived to guide the decision on case study selection. 


\subsubsection{Literature Review}

The literature review is an essential part of an academic research project. The review is a careful examination of a body of literature pointing toward the answer to the research question. The purpose of the literature review is to test the research question against what is already known about a certain subject. A good literature review will look at the research that has been done and synthesize or pull together those elements that are similar or most pertinent to the theme that has been chosen. For the purpose of this research, the literature review assisted in investigating the research gaps and central issues in recruitment domain in relation to the failure in SA e-enlistment. In this context, the literature related to problem definition, problem representation, enterprise architecture, requirement engineering, and best practices documentation and reuse was reviewed. Another use of the literature review method was to define the various requirements based on which the POCM and Onto-RPD were designed.

\subsubsection{Document Inspection}

In most cases, a significant amount of data that help locate the problem are embedded in documents. Furthermore, the initial information captured by document inspection method often form the basis on which further research methods are selected. This method was intensively used to capture knowledge about the SA e-enlistment project, including the mission and functions of SA, the SA's organisational structure and recruitment types, the e-government vision and strategic goals of Secureland and the SA, previous work conducted on the SA e-enlistment project, the models for the SA enlistment practice, and the challenges faced in that project. It was also the main data source for extracting the excerpts from the BA enlistment and UCAS case studies in pursuit of capturing recruitment problem concepts and relationships and building the POCM and Onto-RPD artefacts.

\subsubsection{Focus Group}

Focus group is a research method used for idea generation or validation where several informed participants share their point of view on a specific topic or problem. It can generate a broader range of information, and deepen understanding of the topic under discussion. It can be used for validating and verifying the results gained from other research methods. The usefulness of this method lies in: the ability to interview many participants at one specific time thereby saving much time and cost; and the elicitation of information and data from different people perspectives. In this research, two major focus groups were used in different stages. The first one was called "stakeholders focus group" and used in the "explicate problem" and "design and develop artefact" phases. The objective of this focus group was to generate a broad range of recruitment problem concepts and relationships from different stakeholders' perspectives, and elaborate on them towards a deeper understanding of the recruitment problems faced in the case studies. The second focus group was called "experts focus group" and used during the phase of "demonstrate and evaluate artefact" to evaluate the POCM and Onto-RPD against the set of requirements defined in the "define requirements".

\section{Development of POCM and Onto-RPD}

The development of POCM and Onto-RPD artefacts underwent three A-R cycles. In each A-R cycle, a specific case study was used with a set of research methods for analysis. The artefacts were not simply developed by a matter of consolidating partial vocabularies from the literature, but through bottom-up analysis of data using many techniques associated with the development of grounded theory.

The first A-R cycle was initiated by the analysis of the SA enlistment case study using the Checkland's Soft Systems Methodology (SSM) [92] as an approach (i.e., research framework): (1) to capture the different worldviews of enterprise recruitment problem; (2) to develop the root problem definitions and the multiple entities (i.e., participating roles) in enterprise recruitment; and (3) to develop the first tentative POCM and Onto-RPD artefacts. The first version of the POCM and 
early outputs of this research were presented in previous publications of the authors [16,93]. Different problem analysis techniques such as Rich Pictures, CATWOE (Customers, Actors, Transformation process, Worldview, Owners and Environmental constraints), 5 Whys, and Cause-Effect analysis were used at this cycle. That version was later refined and supported by a corresponding Onto-RPD for more elaboration using text analysis from the other case studies. In the second A-R cycle, the BA enlistment case study was analysed using content/text analysis to capture the various root recruitment problem concepts. These resulting concepts were used to refine the first tentative POCM and Onto-RPD artefacts. The refined versions of POCM and Onto-RPD were presented in [94]. Similarly, the third A-R cycle was to analyse and extract the concepts from the UCAS case study to refine the second tentative POCM and Onto-RPD created in the second A-R cycle. To extract recruitment problem concepts during all A-R cycles, different problem analysis techniques and encapsulation guidelines were used. Figure 2 illustrates the incremental process of building the POCM and Onto-RPD.

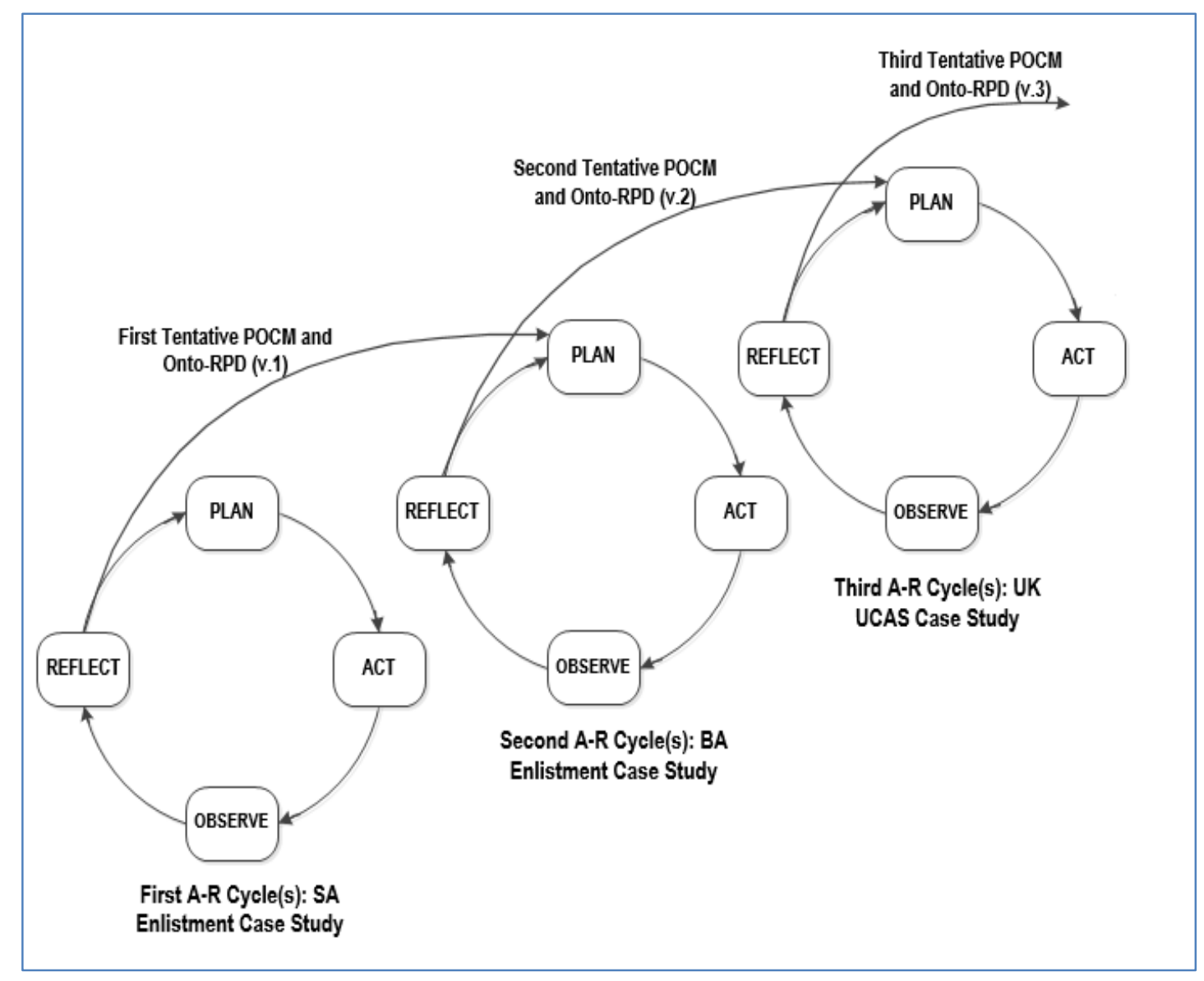

Figure 2. The process of artefact development.

The final improved versions of POCM, Onto-RPD, and root problem definitions are presented in this article. The methodological framework for exploring, capturing, and abstracting recruitment problem, and building the POCM and Onto-RPD artefacts is presented in Figure 3. The framework is inspired by Soft Systems Methodology (SSM) as an approach to understand and explore recruitment problem as a learning system [67]. SSM, a well-known methodology, provides principles, techniques, and guidelines to capture the various system worldviews in a problematic situation, and then develop purposeful activity models (each built to encapsulate a single worldview) as intellectual devices for learning and intervention [92]. According to Checkland and Poulter [67], these principles, techniques, and guidelines of SSM can be adopted and adapted for use in any real situation. 


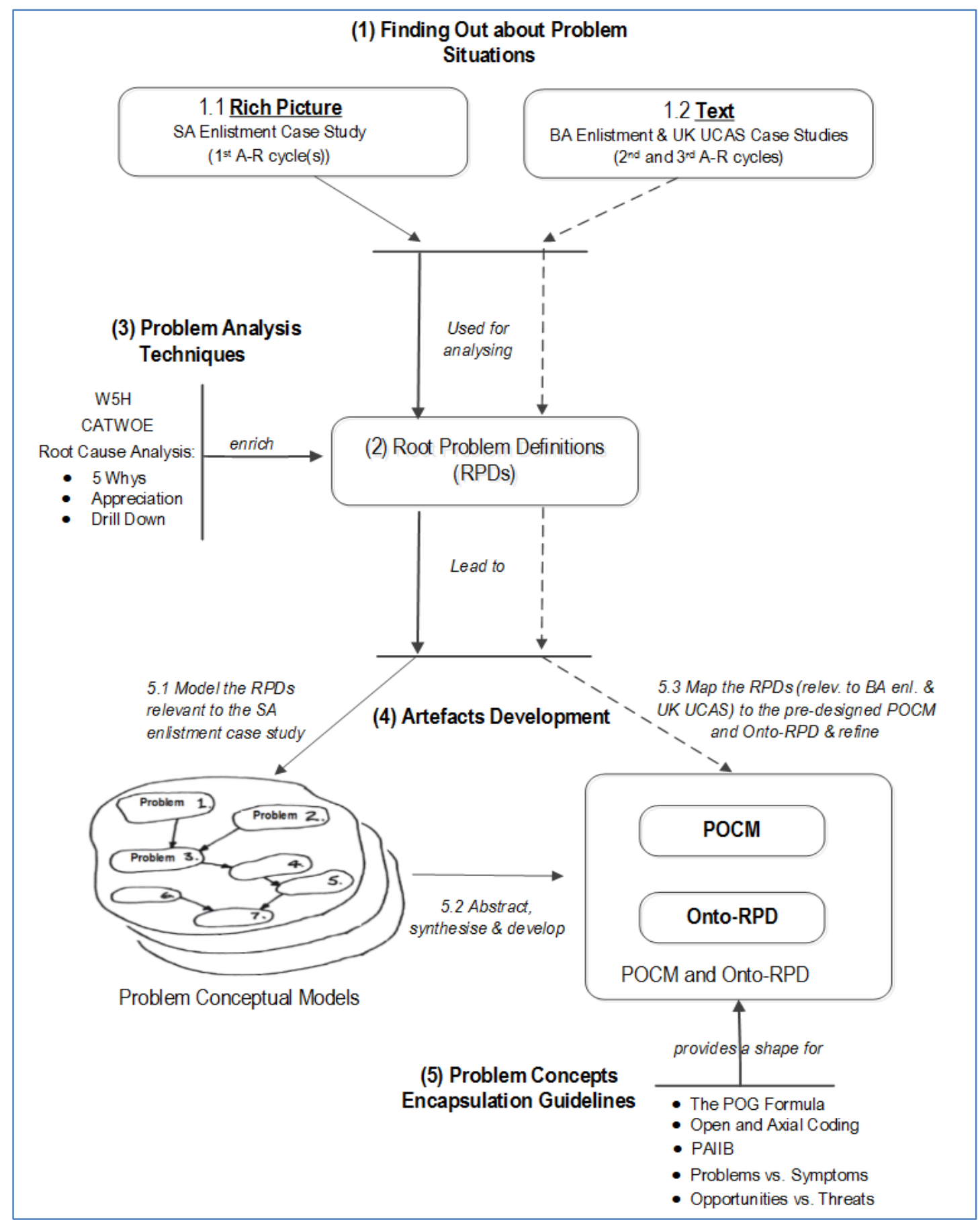

Figure 3. The methodological framework for building POCM and Onto-RPD artefacts.

The POCM is a high-level Problem-Oriented Conceptual Model derived from the various root problem definitions (RPDs) captured from the analysis of the three case studies. The constructs comprising the POCM are the most common problem abstractions and their relationships that often appear in a recruitment problem represented in reference to the proposed definition of recruitment adopted. On the other hand, the Onto-RPD is a complementary ontology that conceptualises the whole recruitment problem space and that helps understand and define a recruitment problem. The process of building these two artefacts is evolutionary through the analysis of the case studies selected. The final (output of the third cycle) POCM, produced from all case studies, is illustrated in Figure 4 . The problem types extracted from the three case studies to develop the conceptual model are explained in Table 1. 
These examples give insights into the problem concepts captured and their influential relationships. The ontology of recruitment problem definition is given in Figure 5. Some of the most important definitions (i.e., glossary) of root problem concepts within the POCM and Onto-RPD are provided in Table 2.

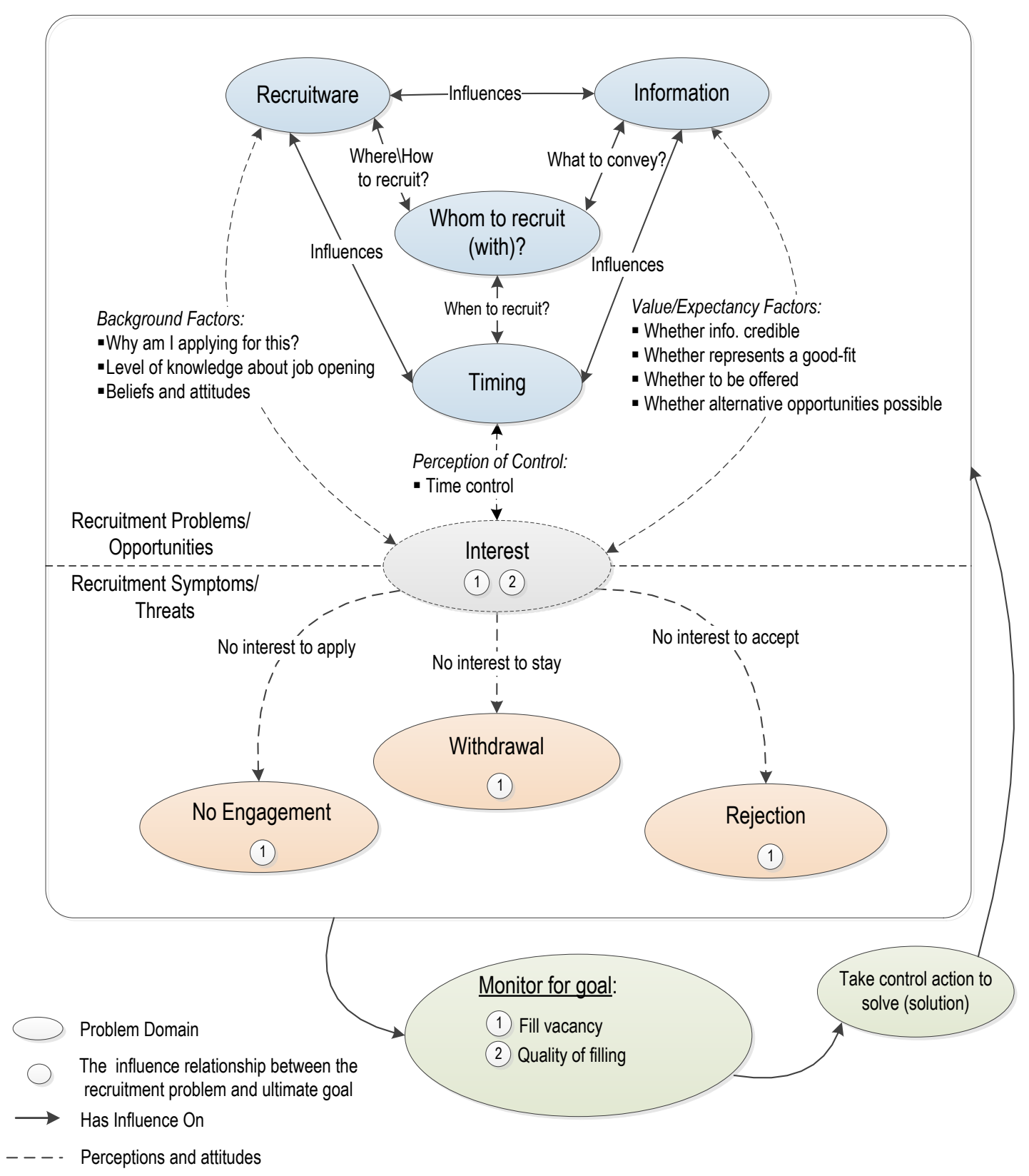

Figure 4. Problem-oriented conceptual model (POCM) for recruitment problem [94]. 
Table 1. Mapping the types of problems from different case studies into the POCM [94].

\begin{tabular}{|c|c|c|c|}
\hline Category & SA Case Study & BA Case Study & UCAS Case Study \\
\hline $\begin{array}{l}\text { Recruitware- } \\
\text { Information }\end{array}$ & $\begin{array}{l}\text { Paper based } \\
\text { announcement restricts } \\
\text { availability of information }\end{array}$ & $\begin{array}{l}\text { Less visibility of armed } \\
\text { forces needs much } \\
\text { information be disclosed }\end{array}$ & $\begin{array}{l}\text { Different tools with different } \\
\text { modes of information } \\
\text { delivery }\end{array}$ \\
\hline $\begin{array}{l}\text { Recruitware- } \\
\text { Whom to recruit }\end{array}$ & $\begin{array}{l}\text { Job locations are remote } \\
\text { from local applicants }\end{array}$ & $\begin{array}{l}\text { We try to minimise the } \\
\text { impact of mobility on } \\
\text { applicants }\end{array}$ & $\begin{array}{l}\text { Improved reach of UCAS } \\
\text { services across social classes }\end{array}$ \\
\hline $\begin{array}{l}\text { Recruitware- } \\
\text { Timing }\end{array}$ & $\begin{array}{l}\text { Hard to build a strong } \\
\text { relationship in a short time }\end{array}$ & $\begin{array}{l}\text { Loss of timely support } \\
\text { needed by other partners }\end{array}$ & $\begin{array}{l}\text { Possible adjustment after } \\
\text { exam results (Adjust service) }\end{array}$ \\
\hline $\begin{array}{l}\text { Timing- } \\
\text { Information }\end{array}$ & $\begin{array}{l}\text { Less time to explore job } \\
\text { opportunities }\end{array}$ & $\begin{array}{l}\text { Successive provision of } \\
\text { job characteristics } \\
\text { offered during } \\
\text { recruitment process }\end{array}$ & $\begin{array}{l}\text { Up-to-date information, } \\
\text { advice and guidance (IAG) }\end{array}$ \\
\hline $\begin{array}{l}\text { Whom to recruit- } \\
\text { Information }\end{array}$ & $\begin{array}{l}\text { High probability of being } \\
\text { offered undesired job } \\
\text { because of diversity } \\
\text { considerations }\end{array}$ & $\begin{array}{l}\text { Some information that } \\
\text { might persuade potential } \\
\text { recruits to enlisting is not } \\
\text { routinely volunteered }\end{array}$ & $\begin{array}{l}\text { Undesirable divide between } \\
\text { those applicants who receive } \\
\text { effective advice and those } \\
\text { who do not }\end{array}$ \\
\hline $\begin{array}{l}\text { Whom to recruit- } \\
\text { Timing }\end{array}$ & $\begin{array}{l}\text { Extra time must be } \\
\text { available for remote } \\
\text { applicants }\end{array}$ & $\begin{array}{l}\text { Ongoing marketing } \\
\text { campaigns for different } \\
\text { categories of applicant }\end{array}$ & $\begin{array}{l}\text { Predefined deadlines for } \\
\text { different applicants to apply } \\
\text { and reply }\end{array}$ \\
\hline $\begin{array}{l}\text { Information- } \\
\text { Interest }\end{array}$ & $\begin{array}{l}\text { Only those who are } \\
\text { well-informed about the } \\
\text { army and its structure can } \\
\text { predict the location of job }\end{array}$ & $\begin{array}{l}\text { The terms of service are } \\
\text { extremely confusing and } \\
\text { subject to many } \\
\text { probabilities }\end{array}$ & $\begin{array}{l}\text { Clear entry requirements } \\
\text { promote accurate } \\
\text { expectation }\end{array}$ \\
\hline $\begin{array}{l}\text { Recruitware- } \\
\text { Interest }\end{array}$ & $\begin{array}{l}\text { Conceived interest in } \\
\text { defending the country } \\
\text { needs to be met by reliable } \\
\text { enlisting practices }\end{array}$ & $\begin{array}{l}\text { Negative publicity from } \\
\text { Afghanistan and Iraq } \\
\text { might not persuade } \\
\text { potential recruits to } \\
\text { enlisting }\end{array}$ & Apply with 5 course options \\
\hline $\begin{array}{l}\text { Timing- } \\
\text { Interest }\end{array}$ & $\begin{array}{l}\text { Post-result recruitment } \\
\text { does not allow much time } \\
\text { to decide }\end{array}$ & $\begin{array}{l}\text { Career appeals } \\
\text { progressively less as } \\
\text { potential recruits grow } \\
\text { into adulthood }\end{array}$ & $\begin{array}{l}\text { Many applicants were happy } \\
\text { with pre-result application } \\
\text { (using predicted grades) }\end{array}$ \\
\hline
\end{tabular}




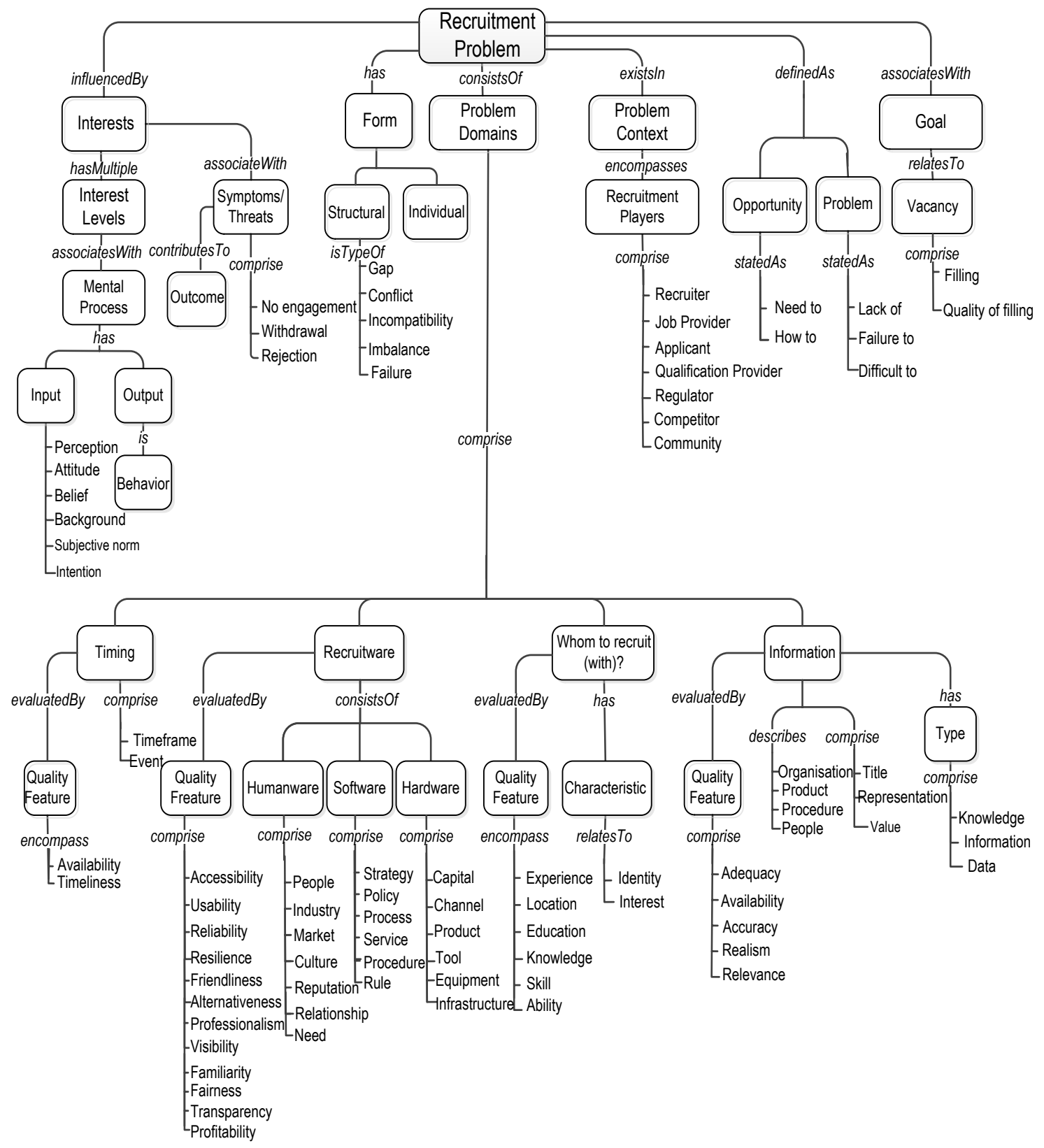

Figure 5. The ontology of recruitment problem definition (Onto-RPD) [94]. 
Table 2. Selected definitions of root problem concepts within the POCM and Onto-RPD artefacts.

\begin{tabular}{|c|c|}
\hline Terms & Definitions \\
\hline Applicant & A person who is being considered for a job at an organization. \\
\hline Hardware & $\begin{array}{l}\text { A general term that includes all physical elements (i.e., physical assets) used or } \\
\text { produced by a recruitment actor that can be seen, touched, and controlled. }\end{array}$ \\
\hline Humanware & $\begin{array}{l}\text { A general term that includes all human-related aspects that describe a } \\
\text { recruitment actor and influence the use of hardware and software. }\end{array}$ \\
\hline Information & $\begin{array}{l}\text { Described as a problem owned by all recruitment actors in which: their } \\
\text { information revealed through controllable and non-controllable communication } \\
\text { fail to/need to influence the others' interests assessed by a set of quality } \\
\text { features (e.g., availability, adequacy, relevance, etc.) taking into account all } \\
\text { influences of other problem domains. This problem domain can be referred to } \\
\text { as Communicated Identity. }\end{array}$ \\
\hline Interest & $\begin{array}{l}\text { Described as a problem owned by all recruitment actors in which: they perceive } \\
\text { that recruitware, information, and timing fall short to influence the intentions to } \\
\text { react positively assessed by a set of factors (e.g., value/expectancy and } \\
\text { background factors). This problem domain can be referred to as } \\
\text { Conceived Identity. }\end{array}$ \\
\hline $\begin{array}{l}\text { Rejection/ } \\
\text { Withdrawal/ } \\
\text { no engagement }\end{array}$ & $\begin{array}{l}\text { Described as problem owned by all recruitment actors in which their } \\
\text { behaviours/actions influence filling of vacancy. No engagement is when there } \\
\text { is no action carried out by the actor; withdrawal is when the actor withdraw } \\
\text { out of interaction); and rejection is when the actor send an actual rejection } \\
\text { message to an offer. }\end{array}$ \\
\hline Problem Context & The area in which a problem exists. \\
\hline Problem Domain & A way of considering or conceptualising problem. \\
\hline Quality Feature & A distinctive attribute or characteristic possessed by someone or something. \\
\hline Recruitment & $\begin{array}{l}\text { An enterprise system in which different players interact according to their } \\
\text { interests to fill a job vacancy. }\end{array}$ \\
\hline Recruitment Problem & $\begin{array}{l}\text { A problematic situation with a recruitment practice regarded as undesired that } \\
\text { needs to be defined to overcome. }\end{array}$ \\
\hline Recruitware & $\begin{array}{l}\text { Described as a problem owned by all recruitment actors in which: their current } \\
\text { attributes, shaped by a number of elements, fail to/need to influence the others' } \\
\text { interests assessed by a set of quality features taking into account the impact of } \\
\text { the other problem domains. This problem domain can be referred to as Actual } \\
\text { Identity. }\end{array}$ \\
\hline Timing & $\begin{array}{l}\text { Described as a problem owned by all recruitment actors in which: the timings } \\
\text { of events fail to/need to influence the others' interests assessed by a set of } \\
\text { quality features (e.g., availability, responsiveness, timeliness, etc.) taking into } \\
\text { account all influences of other problem domains. This can be referred to as } \\
\text { Timed Identity. }\end{array}$ \\
\hline Whom to recruit (with) & $\begin{array}{l}\text { Described as a problem owned by all recruitment actors in which their } \\
\text { decisions in regard to the optimum recruitment partner to recruit with to fill a } \\
\text { specific vacancy influence/influenced by recruitware, information, and timing } \\
\text { taken into account the external factors e.g., social, economic, political, } \\
\text { technological, legal, etc. }\end{array}$ \\
\hline
\end{tabular}

\section{Demonstration and Evaluation of POCM and Onto-RPD}

In this section, the demonstration and evaluation of the POCM and Onto-RPD are presented. The demonstration phase is to use the POCM and Onto-RPD artefacts in real-life cases to prove their feasibility. The evaluation phase is to examine how well the POCM and Onto-RPD have contributed to address the practical problems explicated and whether they have achieved the defined requirements. The two phases were conducted using one focus group through two sessions on the same day. 


\subsection{Demonstration}

In this phase, participants were selected from Bournemouth University (academic and practitioners) with different recruitment-related experiences (e.g., HR, management, marketing, psychology, sociology, etc.). The participants were identified using BU staff database and an invitation poster based on the following conditions: participants should have at least three years of recruitment-relevant experience and they should be either an academic expert (teaching staff or PhD students) or a practitioner. After a careful survey of Bournemouth staff database, potential participants were selected according to the expertise in recruitment. After the selection, they were invited using email to participate in research with a chance of winning a 20 Pound voucher from Amazon. The poster was supported with a chance of winning the voucher as well. The poster was distributed through the boards around the public places at Bournemouth University. The purpose of the poster was to widen participation and gain access to those cannot be reached through the BU staff database.

The number of selected participants through the poster was nine, while the number of those selected through the BU staff database was 54 . The total number of target participants was 63. A group of 16 people accepted the invitation. In preparation of demonstration session, the participants were requested, as an assignment, to write a short description of a recruitment problem case they faced. Only four problem cases were collected. These cases were then revised and circulated to others being asked to comment on them and define the potential problems with each case from their perspectives. The answers were collected and prepared for use in the demonstration session.

Due to the difficulty to arrange the demonstration meeting and get a consensus among all 16 participants on the time and location of session, only 10 participants were invited. The session started by welcoming the participants and subsequently several activities were conducted towards the achievement of session purpose. The themes of research; the artefacts to be evaluated; the way by which this focus group research is conducted; the way the research materials (templates) are used for answers and comments; and the four recruitment case studies to be used in assessment were presented.

The purpose of this session was to demonstrate the POCM and Onto-RPD artefacts to the participants and apply them to the recruitment cases described in the preparation phase to assess their feasibility. Based on that, the participants were asked to loudly elaborate on each case study (i.e., defining related potential problems) keying on the list of problem definitions presented with each case. For a better elaboration, the participants were asked to use the journalist's questions (e.g., what, why, where, when, who, which, and how). Meanwhile, the participants were directed to the POCM and Onto-RPD artefacts being asked to populate or relate their proposed problem definitions to the concepts on the artefacts, or reversely to use the artefacts' concepts for the knowledge retrieval and define new recruitment problems.

At the end of the discussion on each case study, participants were given time to assess the application of POCM and Onto-RPD artefacts to each case study, and answer a list of semi-structured questions in the templates prepared for that purpose. The participants were also asked to write down their comments and suggestions. The questions were to assess the feasibility and contributions of the artefacts in the following:

- Definition of key recruitment problem concepts embedded in a recruitment case study

- Inclusion and integration of many recruitment stakeholders' perspectives

- Capturing and representation of the problem situational structure in each case study and its relationships

- Better recruitment problem understanding and analysis towards solving recruitment problem

\subsection{Evaluation}

After the demonstration and assessment of POCM and Onto-RPD across each case study, the purpose of this session was to generally examine how well the POCM and Onto-RPD artefacts addressed the practical problems explicated and whether they achieved the predefined requirements. 
In the evaluation session, participants were asked to write down their comments on the overall contribution of the artefacts to the requirements prescribed based on the results of application in the demonstration session. The participants were provided with templates for that purpose. These comments were openly discussed in a group to come up with new ideas and suggestions for improving the artefacts. At the end of session, the participants were asked to add any suggestions and recommendation for improving the artefacts.

\subsection{Key Findings from the Evaluation}

The data obtained from the focus group sessions were analysed qualitatively through content analysis. To conduct the qualitative content analysis, the study started by selecting appropriate texts from the templates of the evaluation session, analysing the texts, verifying their relation to the requirements categories, comparing them to the results of application in the demonstration session, and finally presenting them. The results of analysis are presented, as follows:

- Comprehensive: Three experts clearly stated that the POCM and Onto-RPD artefacts offer complete coverage of the knowledge in the recruitment problem domain. For example, one respondent commented "it is impressive, I can say that your models (i.e., POCM and Onto-RPD) are quite full". A second respondent stated "they (artefacts) are complete and all problem categories and recruitment actors are relevant". In contrast, only one respondent criticised the artefacts for this requirement reporting "it is better to have one comprehensive model rather than a combination of two models ... the POCM was little vague to me until I referred to the Onto-RPD and glossary". For this issue, we believe that a real-world recruitment problem has various concepts and relationships that cannot be comprehensively represented in one reference model [58,68]. Hence, we developed a specific POCM for representing problem-related concepts and relationships, and then we supported it with a complementary ontology (Onto-RPD) for the definition of other domain-relevant concepts.

- Generic: Six experts confirmed that the POCM and Onto-RPD artefacts are shared and sector-independent, however, with some suggestions. One stated "you addressed the entire picture of a recruitment problem including many stakeholders' perspectives and problem viewpoints ... there is no odd concept or chance for any to be sector-specific". A second respondent reported "I think the applicability of models to the four case studies from different industries in the last session has already justified this". However, some criticism was present. Some respondents argued that a level of specificity in regard to selection and interview processes as well as job attributes would better support analysis of recruitment problem. Another argued that a variety of stakeholders' goals may exist in a recruitment problem situation, therefore, the goal of recruitment (fill vacancy) is very limited. In regard to specificity, we agree on the need of some specificity in certain situations. However, specificity is always in conflict with the requirement of "abstract" (which implies that concepts need to be generalised and instantiated over many levels of analysis. Hence, some of the specific concepts related to selection and interview and job attributes are generalised to enable mapping to other analysis levels. For the goal "fill vacancy", it is based on the concept of SSM that defines recruitment problem as a system whose emergent property is its purposefulness or its ultimate outcome, i.e., filling a job vacancy. Thus, this goal was emergent while other stakeholders' goals were implied in the POCM as problem-oriented concepts. From an enterprise perspective, we focused on the ultimate shared goal for which all enterprise actors shall cooperate to achieve increasing labour market share, while also defining all other goals (i.e., conflicts) that impede the achievement of this goal from problem-oriented perspective.

- Consistent: Most experts agreed that the POCM and Onto-RPD artefacts have correct and accurate concepts compared to the exiting knowledge in the recruitment domain. For instance, one confirmed "the terms in the artefacts are correct and the classifications are consistent". However, one expert commented "the term of recruitware is new, it would be better to use more 
common one". However, the term "recruitware" refers to the concepts: humanware, software, and hardware. These three concepts are used in recruitment domain (see [95]). Hence, it is arguably suitable for coding these concepts as recruitware in reference to the recruitment assets.

- Abstract/granular: Three experts confirmed that the POCM is abstract and can be instantiated different level of analysis. One commented "I like the way you encapsulated the concepts of recruitment problem and relationships in your POCM model .... I think this is the best part of your work". Another stated "the representation of recruitment problem as interest conflicts between a wide range of recruitment actors through different types of identities can be mapped into different levels of analysis". In contrast, one argued "the POCM is good for management problems".

- Perspicacious: Five experts agreed that the POCM and Onto-RPD are easily understood and consistently applied by practitioners. For example, one respondent confirmed "many problem scenarios have been applied which makes clear that the POCM and Onto-RPD are very effective in this part". A second one stated "I can understand where the conflicts might happen". A third one reported "indeed, we know little about recruitment problem and the way we recruit was just a shot in the dark! ... such models are very helpful to understand and learn about the complexity of a recruitment problem and the size of work needed". A fourth one stated "the POCM and Onto-RPD give insights into different problem aspects and relationships that might be trivialised by a stakeholder". However, some criticisms were reported. For example, one stated "the artefacts are descriptive ... they need to be formal for a better insight into problem solving". Another implied "the artefacts lack a step-by-step method to define the problem". For the formality issue, we argue that a problem representational model shall not be formal, but of a qualitative nature to corresponds to the nature of a real-world recruitment problem being conceptual [24,57]. However, for the lack of a step-by-step method, the artefacts we built best served as "a reference model" for recruitment problem representation. To make these artefacts more generative, they need "a methodology" to guide analysis and definition of recruitment problem and then transform it to the solution using different techniques and through different levels of abstraction. The development of such a methodology is out of the scope of this paper.

- Minimal: Three experts confirmed that the POCM and onto-RPD artefacts contain the minimum number of objects. One stated "I think the models have covered the most important aspects of a recruitment problem". Another stated "despite the conflict between comprehensiveness and minimal, the artefacts provide a balanced set of recruitment problem concepts".

\section{Conclusions}

In this paper, we respond to the gap in recruitment problem representation by developing two artefacts: a problem-oriented conceptual model (POCM) and related ontology for recruitment problem definition (Onto-RPD). Both artefacts were derived from the analysis of empirical data from three real recruitment case studies and abstraction of fundamental problem concepts and their underlying structures using various problem analysis techniques and guidelines. The POCM is proposed for contextualising the various problem concepts and their relationships of recruitment problem. The Onto-RPD provides a comprehensive definition of recruitment problem by relating the POCM's concepts to the other problem space concepts. By means of the POCM and Onto-RPD artefacts, one can account for the huge variety of recruitment problem definitions (i.e., problem types and their underlying structures) proposed by different stakeholders for a given problematic recruitment situation. The identification and representation of which will promote a comprehensive definition of recruitment problem and a better understanding of how recruitment problem may emerge, develop, and change over time. Future work will focus on developing s systematic approach (POCM-based guidance) of how the POCM and its related Onto-RPD artefacts can be used with other established approaches of RE for realising the value of e-recruitment solutions. 
Author Contributions: S.A. is a PhD researcher who conducted the methods to develop the conceptual model and ontology. H.D. and K.P. provided supervision and guidance on how to apply the methods in addition to reviewing the paper. N.J. supported the validation of the outputs during the focus groups. D.C. contributed to the outline and hence coherence of the paper. N.J. and D.C. also reviewed the paper.

Funding: This research received no external funding.

Conflicts of Interest: The authors declare no conflict of interest.

\section{References}

1. Bowen, D.; Ostroff, C. Understanding HRM-Firm performance linkages: The role of the 'strength' of the HRM system. Acad. Manag. Rev. 2004, 29, 203-221.

2. Ployhart, R.E.; Nyberg, A.J.; Reilly, G.; Maltarich, M.A. Human capital is dead; long live human capital resources. J. Manag. 2014, 40, 371-398. [CrossRef]

3. Ray, G.; Muhanna, W.; Barney, J. Competing with IT: The role of shared IT-business understanding. Commun. ACM 2007, 50, 87-91. [CrossRef]

4. Ahmed, S.; Adams, A. Web Recruiting in Government Organisations: A case Study of the Northern Kentucky/Greater Cincinnati Metropolitan Region. Public Perform. Manag. Rev. 2010, 33, 653-670. [CrossRef]

5. Rynes, S.L.; Cable, D.M. Recruitment research in the twenty first century. In Handbook of Psychology: Industrial and Organisational Psychology; Borman, W.C., Ilgen, D.R., Klimoski, R.J., Eds.; Wiley: New York, NY, USA, 2003; Volume 12, pp. 55-76.

6. Gatewood, R.; Field, H.; Barrick, M. Human Resource Selection, 6th ed.; Cengage/South-Western: Mason, $\mathrm{OH}$, USA, 2008.

7. Breaugh, J.; Starke, M. Research on Employee Recruitment: So Many Studies, So Many Remaining Questions. J. Manag. 2000, 26, 405-434. [CrossRef]

8. Tresch, T. Challenges in the recruitment of professional soldiers in Europe. In Strategic Impact; Vasile, P., Corina, V., George, R., Eds.; National Defence University: Romania, Balkans, 2008; Volume 3, pp. 76-86.

9. Pfieffelmann, B.; Wagner, S.; Libkuman, T. Recruiting on corporate web sites: Perceptions of fit and attraction. Int. J. Sel. Assess. 2010, 18, 40-47. [CrossRef]

10. Llorens, J.; Kellough, J. A revolution in public personnel administration: The growth of web-based recruitment and selection processes in the federal service. Public Pers. Manag. 2007, 36, 207-221. [CrossRef]

11. Young, J.; Foot, K. Corporate E-recruiting: The construction of work in fortune 500 recruiting web sites. J. Comput.-Med. Commun. 2005, 11, 44-71. [CrossRef]

12. NATO. Research and Technology Organisation, Recruiting and Retention of Military Personal; Final Report of Research Task Group HFM-107; Neuilly-Sur-Seine Cedex: Paris, France, 2007.

13. Smaliukienè, R.; Trifonovas, S. E-recruitment in the Military: Challenges and Opportunities for Development. J. Secur. Sustain. Issues 2012, 1, 299-307. [CrossRef]

14. Kerrin, M.; Kettley, P. E-recruitment: Is It Delivering? Institute for Employment Studies Report No. 401; Institute for Employment Studies: London, UK, 2003.

15. Kim, S.; O'Connor, J. Assessing electronic-recruitment implementation in state governments: Issues and challenges. Public Pers. Manag. 2009, 35, 47-66. [CrossRef]

16. Alamro, S.; Dogan, H.; Phalp, K. E-military recruitment: A conceptual model for contextualizing the problem domain. In Information Systems Development: Transforming Organisations and Society through Information Systems; Strahonja, V., Vrček, N., Plantak, V., Barry, C., Lang, M., Linger, H., Schneider, C., Eds.; University of Zagreb: Varaždin, Croatia, 2014.

17. Sharp, H.; Rogers, Y.; Preece, J. Interaction Design: Beyond Human-Computer Interaction; John Wiley \& Sons: Hoboken, NJ, USA, 2007.

18. Bray, I. An Introduction to Requirements Engineering; Addison Wesley: Boston, MA, USA, 2002.

19. Mikalef, P.; Framnes, V.A.; Danielsen, F.; Krogstie, J.; Olsen, D.H. Big data analytics capability: Antecedents and business value. In Proceedings of the 21st Pacific Asia Conference on Information Systems (PACIS), Langkawi, Malaysia, 16-20 July 2017.

20. Nuseibeh, B.; Easterbrook, S. Requirements engineering: A roadmap. In Proceedings of the IEEE International Conference on the Future of Software Engineering (ICSE), Limerick, Ireland, 4-11 June 2000; pp. 35-46. 
21. Viller, S.; Sommerville, I. Ethnographically informed analysis for software engineers. IJHCS 2000, 53, $169-196$. [CrossRef]

22. Siegemund, K. Contributions to Ontology-Driven Requirements Engineering. Ph.D. Thesis, Technische Universität Dresden, Dresden, Germany, 2014; p. 109.

23. Martin, D.; Sommerville, I. Patterns of Cooperative Interaction: Linking Ethnomethodology and Design. ACM Trans. Comput.-Hum. Interact. 2004, 11, 59-89. [CrossRef]

24. Smith, G. Defining Real World Problems: A conceptual language. IEEE Trans. Syst. Man Cypernetics 1993, 23, 1220-1234. [CrossRef]

25. Jackson, M. Problem Frames: Analysing and Structuring Software Development Problems; Addison-Wesley: Boston, MA, USA, 2001.

26. Fouad, A. Embedding Requirements within the Model Driven Architecture. Ph.D. Thesis, Bournemouth University, Poole, UK, 2011.

27. Kossmann, M.; Odeh, M. Ontology-driven requirements engineering a case study of OntoREM in the aerospace context. In Proceedings of the INCOSE Conference 2010, Chicago, IL, USA, 12-15 July 2010.

28. Zachman, J. The Concise Definition of the Zachman Framework, 2008. Available online: https://www. zachman.com/about-the-zachman-framework (accessed on 10 October 2018).

29. Hull, E.; Jackson, K.; Dick, J. Requirements Engineering, 3rd ed.; Springer: London, UK, 2011.

30. Neetu, K.; Pillai, A. A Survey on Global Requirements Elicitation Issues and Proposed Research Framework; ICSESS: Beijing, China, 2013; pp. 554-557.

31. Saks, A.M. The impracticality of recruitment research. In Handbook of Personnel Selection; Evers, A., Smit-Voskuyl, O., Anderson, N., Eds.; Basil Blackwell: Oxford, UK, 2005; pp. 47-72.

32. Breaugh, J.A. Employee recruitment: Current knowledge suggestions for future research In The Oxford Handbook of Personnel Assessment and Selection; Schmitt, N., Ed.; Oxford University Press: New York, NY, USA, 2012; pp. 68-87.

33. Ployhart, R. Staffing in the 21st century: New challenges and strategic opportunities. J. Manag. 2006, 32, 868-897. [CrossRef]

34. Randall, S. Personnel and Human Resource Management, 3rd ed.; West: Eagan, MN, USA, 1987.

35. Barber, A. Recruiting Employees; Sage Publications: Thousand Oaks, CA, USA, 1998.

36. Rynes, S. Recruitment, job choice, and post-hire consequences. In Handbook of Industrial and Organisational Psychology, 2nd ed.; Dunnette, M., Ed.; Consulting Psychologists Press: Palo Alto, CA, USA, 1991; pp. $399-444$.

37. Phillips, J.; Gully, S. Multilevel and strategic recruiting where have we been, where can we go from here. J. Manag. 2015, 41, 1416-1445.

38. Ghazzawi, K.; Accoumeh, A. Critical success factors of the e-recruitment system. J. Hum. Resour. Manag. Labor Stud. 2014, 2, 159-170.

39. Dhamija, P. E-recruitment: A roadmap towards e-human resource management. Res. World 2012, 3, 33.

40. Lee, I. Evaluation of fortune 100 companies' career Web sites. Hum. Syst. Manag. 2005, 24, 175-182.

41. Braddy, P.W.; Meade, A.W.; Kroustalis, C.M. Organisational recruitment website effects on viewers' perceptions of organizational culture. J. Bus. Psychol. 2006, 20, 525-543. [CrossRef]

42. Steel, E. Job search sites face a nimble threat. Wall Str. J. B 2007, 10. Available online: https:/ /www.wsj.com/ articles/SB119189368160253014 (accessed on 10 October 2018).

43. Ladkin, A.; Buhalis, D. Online and social media recruitment. Int. J. Contemp. Hosp. Manag. 2016, 28, 327-345. [CrossRef]

44. Taylor, M.S.; Collins, C. Organisational recruitment: Enhancing the intersection of research and practice. In Industrial and Organisational Psychology; Cooper, C., Locke, E.A., Eds.; Blackwell: Oxford, UK, 2000; pp. 304-334.

45. Vidgen, R.; Shaw, S.; Grant, D.B. Management challenges in creating value from business analytics. Eur. J. Oper. Res. 2017, 261, 626-639. [CrossRef]

46. De Mauro, A.; Greco, M.; Grimaldi, M.; Ritala, P. Human resources for Big Data professions: A systematic classification of job roles and required skill sets. Inf. Process. Manag. 2018, 54, 807-817. [CrossRef]

47. Mikalef, P.; Giannakos, M.N.; Pappas, I.O.; Krogstie, J. The human side of big data: Understanding the skills of the data scientist in education and industry. In Proceedings of the Global Engineering Education Conference (EDUCON) 2018, Tenerife, Spain, 17-20 April 2018; pp. 503-512. 
48. Scheweyer, A. Talent Management Systems: Best Practices in Technology Solutions for Recruitment, Retention and Workforce Planning; Wiley: New York, NY, USA, 2004.

49. Osigweh, C. Puzzles or problems? Cutting through the manager's dilemma. Bus. Horiz. 1985, 28, 69-73.

50. Landry, M. A note on the concept of problem. Organ. Stud. 1995, 16, 315-343. [CrossRef]

51. Agre, G. The concept of problem. Educ. Stud. 1982, 13, 121-142. [CrossRef]

52. Davis, A. Software Requirements: Objects, Functions, and States; Prentice Hall: Hemel Hempstead, UK, 1993.

53. Kovitz, B. Practical Software Requirements: A Manual of Content and Style; Manning: Greenwich, CT, USA, 1999.

54. Zave, P. Classification of Research Efforts in Requirements Engineering. ACM Comput. Surv. 1997, 29, 315-321. [CrossRef]

55. Kotonya, G.; Sommerville, I. Requirements Engineering: Processes and Techniques; Wiley: Chichester, UK, 1998.

56. Wieringa, R. Requirements Engineering: Problem Analysis and Solution Specification. In ICWE 2004, LNCS 3140; Koch, N., Fraternali, P., Wirsing, M., Eds.; Springer-Verlag: Berlin/Heidelberg, Germany, 2004; pp. 13-16.

57. Smith, G.F. Defining Managerial Problems: A Framework for Prescriptive Theorizing. Manag. Sci. 1989, 8, 963-981. [CrossRef]

58. Pedell, S.; Miller, T.; Vetere, F.; Sterling, L.; Howard, S. Socially-Oriented Requirements Engineering: Software Engineering Meets Ethnography. In Perspectives on Culture and Agent-Based Simulations, Studies in the Philosophy of Sociality 3; Dignum, V., Dignum, F., Eds.; Springer International Publishing: Cham, Switzerland, 2014.

59. Kavakli, E. Modelling Organizational Goals: Analysis of Current Methods. In Proceedings of the ACM Symposium on Applied Computing, Nicosia, Cyprus, 14-17 March 2004.

60. Hall, J.G.; Rapanotti, L.; Jackson, M. Problem Oriented Software Engineering: Solving the Package Router Control Problem. IEEE Trans. Softw. Eng. 2008, 34, 226-241. [CrossRef]

61. Sessions, R. A Comparison of the Top Four Enterprise Architecture Frameworks. 2007. Available online: http:/ / www3.cis.gsu.edu/dtruex/courses/CIS8090/2013Articles / A\%20Comparison\%20of\%20the\% 20Top\%20Four\%20Enterprise-Architecture\%20Methodologies.html (accessed on 10 October 2018).

62. Zachman, J. Zachman International: Enterprise Architecture. 2015. Available online: https://www.zachman. com/about-the-zachman-framework (accessed on 5 October 2018).

63. Sherwood, J.; Clark, A.; Lynas, D. Enterprise Security Architecture. SABSA Institute, 2005. Available online: https: / / sabsa.org (accessed on 15 October 2018).

64. Vallejo, C.; Romero, D.; Molina, A. Enterprise integration engineering framework and toolbox. Int. J. Prod. Res. 2012, 50, 1489-1511. [CrossRef]

65. Gaver, S. Why Doesn't the Federal Enterprise Architecture Work? Technology Matter Inc., Visited 2016. 2010. Available online: http://www.ech-bpm.ch/sites/default/files/articles/why_doesnt_the_federal_ enterprise_architecture_work.pdf (accessed on 8 October 2018).

66. Bloomberg, J. Is Enterprise Architecture Completely Broken? Forbes Magazine. 2014. Available online: http:/ / www.forbes.com/sites/jasonbloomberg (accessed on 10 October 2018).

67. Checkland, P.; Poulter, J. Soft Systems Methodology. In Systems Approaches to Managing Change: A Practical Guide; Springer Science \& Business Media: Berlin, Germany, 2010; pp. 191-242.

68. Vergidis, K.; Tiwari, A.; Majeed, B. Business Process Analysis and Optimization: Beyond Reengineering. Systems, Man, and Cybernetics, Part C: Applications and Reviews. IEEE Trans. 2008, 38, 69-82.

69. Osada, A.; Ozawa, D.; Kaiya, H.; Kaijiri, K. The role of domain knowledge representation in requirements elicitation. In Proceedings of the 2007, 25th IASTED International Multi-Conference Software Engineering, Innsbruck, Austriapp, 13-15 February 2007; pp. 84-92.

70. Kettinger, W.; Teng, J.; Guha, S. Business process change: A study of methodologies, techniques, and tools. MIS Q. 1997, 21, 55-80. [CrossRef]

71. Aguilar-Saven, R. Business process modelling: Review and framework. Int. J. Prod. Econ. 2004, 90, 129-149. [CrossRef]

72. Robertson, S.; Robertson, J. Mastering the Requirements Process; Addison-Wesley: Harlow, UK, 2012.

73. Hevner ARMarch, S.T.; Park, J.; Ram, S. Design science in information systems research. MIS Q. 2004, 28, 75-105. [CrossRef]

74. Johannesson, P.; Perjons, E. An Introduction to Design Science; Springer International Publishing: Cham, Switzerland, 2014. 
75. Bider, I.; Johannesson, P.; Perjons, E. Design science research as movement between individual and generic situation-problem-solution spac-es. In Organizational Systems: An Interdisciplinary Discourse; Baskerville, R., de Marco, M., Spagnoletti, P., Eds.; Springer: Berlin/Heidelberg, Germany, 2012.

76. Alturki AGable, G.; Bandara, W. The design science research roadmap: In Progress evaluation. In Proceedings of the Pacific Asia Conference on Information Systems (PACIS), Jeju Island, Korea, 18-22 June 2013.

77. Peffers, K.; Tuunanen, T.; Rothenberger, M.A.; Chatterjee, S. A design science research methodology for information systems research. J. Manag. Inf. Syst. 2007, 24, 45-77. [CrossRef]

78. Kuechler, B.; Vaishnavi, V. On theory development in design science research: Anatomy of a research project. Eur. J. Infor-Mation Syst. 2008, 17, 489-504. [CrossRef]

79. Fox, M.; Barbuceanu, M.; Gruninger, M.; Lin, J. An Organization Ontology for Enterprise Modelling. In Simulating Organizations: Compu-Tational Models of Institutions and Groups; Prietula, M., Carley, L., Gasser, L., Eds.; AAAI/MIT Press: Menlo Park, CA, USA, 1998; pp. 131-152.

80. Burton-Jones, A.; Storey, V.C.; Sugumaran, V.; Ahluwalia, P. A semiotic metrics suite for assessing the quality of ontologies. Data Knowl. Eng. 2004, 55, 84-102. [CrossRef]

81. Smith, F.I.; Kisamore, J.L.; Stone, T.H.; Jawahar, I.M. Decision-Making biases and affective states: Their potential impact on best practice innovations. Can. J. Adm. Sci. ASAC 2010, 27, 277-291. [CrossRef]

82. Vesely, A. Theory and methodology of best practice research: A critical review of the current state. Cent. Eur. J. Public Policy 2011, 2, 98-117.

83. Simard, C.; Rice, R.E. The practice gap: Barriers to the diffusion of best practices. In Re-Thinking Knowledge Management: From Knowledge Objects to Knowledge Processes; McInerney, C.R., Day, R.E., Eds.; Springer-Verlag: Dordrecht, The Netherlands, 2007; pp. 87-124.

84. Porzel, R.; Malaka, R. A Task-based Approach for Ontology Evaluation. Available online: http:/ / citeseerx. ist.psu.edu/viewdoc/download?doi=10.1.1.93.6109\&rep=rep1\&type=pdf (accessed on 15 October 2018).

85. Gruber, T.R. Toward Principles for the Design of Ontologies Used for Knowledge Sharing; Report KSL 93-04; Stanford University: Stanford, CA, USA, 1993.

86. Baskerville, R.; Wood-Harper, A.T. A critical perspective on action research as a method for information systems research. J. Inf. Technol. 1996, 11, 235-246. [CrossRef]

87. Avison, D.; Baskerville, R.; Myers, M. Controlling action research projects. Inf. Technol. People 2001, 4, $28-45$. [CrossRef]

88. Järvinen, P. Action research is similar to design science. Qual. Quant. 2007, 41, 37-54. [CrossRef]

89. Wieringa, R.; Morali, A. Technical action research as a validation method in information systems design science. In Proceedings of the International Conference on Design Science Research in Information Systems and Technology (DESRIST), Las Vegas, NV, USA, 14-15 May 2012; Springer: Berlin, Germany, 2012.

90. Baskerville, R.; Pries-Heje, J.; Venable, J. Soft Design Science Research: Extending the Boundaries of Evaluation in Design Science Research. In Proceedings of the 2nd International Conference on Design Science Research in Information Systems and Technology (DESRIST 2007), Pasadena, CA, USA, 13-15 May 2007.

91. Yin, R. Case Study Research: Design and Methods, 4th ed.; Sage Publishing: Beverly Hills, CA, USA, 2008.

92. Checkland, P.; Scholes, J. Soft Systems Methodology in Action; Wiley: Chichester, UK, 1990.

93. Alamro, S.; Dogan, H.; Phalp, K. Forming enterprise recruitment pattern based on problem-oriented conceptual model. Procedia Comput. Sci. 2015, 64, 298-305. [CrossRef]

94. Alamro, S.; Dogan, H.; Cetinkaya, D.; Jiang, N. Problem-Oriented Conceptual Model and Ontology for Enterprise e-Recruitment. In Proceedings of the 20th International Conference on Enterprise Information Systems (ICEIS), Funchal, Portugal, 21-24 March 2018.

95. Roe, R. The design of selection systems: Context, principles, issues. Handb. Pers. Sel. 2005, 73-97.

(C) 2018 by the authors. Licensee MDPI, Basel, Switzerland. This article is an open access article distributed under the terms and conditions of the Creative Commons Attribution (CC BY) license (http:// creativecommons.org/licenses/by/4.0/). 